\title{
Land use and first birth timing in an agricultural setting
}

\author{
Dirgha J. Ghimire · Lynette F. Hoelter
}

Published online: 22 August 2007

(C) Springer Science+Business Media, LLC 2007

\begin{abstract}
The dramatic changes in the earth's landscape have prompted increased interest in the links between population, land use, and land cover. Previous research emphasized the notion of population pressure (population pressure increases demands on natural resources causing changes in land use), overlooking the potentially important effects of changes in land use on humans. Using multiple data sets from the Chitwan Valley Family Study in Nepal, we test competing hypotheses about the impact of land use on first birth timing. We argue that while agricultural land should encourage early childbearing, land area devoted to public infrastructure should discourage it. The results show that individuals from neighborhoods with larger proportions of land under agriculture experienced first birth at rates higher than those from neighborhoods with smaller proportions. On the other hand, individuals from neighborhoods with larger proportions of land under public infrastructure experienced first birth at rates lower than those from neighborhoods with smaller proportions. However, the effects of public infrastructure are not as strong as the land area devoted to agriculture.
\end{abstract}

Keywords Land use $\cdot$ First birth timing $\cdot$ Agriculture $\cdot$ Nepal

\section{Introduction}

The past century has witnessed dramatic changes in the earth's landscape and natural resources. These dramatic changes have prompted increasing research on land use and land cover change. A large number of studies have successfully documented the extent, intensity, and determinants of land use and land cover

D. J. Ghimire $(\bowtie) \cdot$ L. F. Hoelter

Institute for Social Research, University of Michigan, 426 Thompson St., Ann Arbor,

MI 48106-1248, USA

e-mail: nepdjg@umich.edu 
change (Enwistle et al. 2003; Goldewijk 2001; Lambin 1997; Lambin et al. 2000). Particularly with the application of remote sensing technology, numerous studies have documented the changes in land use and land cover in great detail. While part of the land use and land cover change is a natural process, a large part of these changes are caused by human activities (Liu et al. 2003). Indeed, the dramatic changes in land use and land cover are found to be associated with agriculture (Wolman 1993) mainly for food production (Bongaarts 1992, 1996; Lutz et al. 2002). As a result, the impacts of population pressure on land use and land cover change have drawn a great deal of attention in the research arena.

Although previous studies have been extremely useful in documenting the extent, the intensity, and the determinants of land use and land cover change with great detail, they have been less useful in explaining the consequences of the changes in land use and land cover on humans. With the exception of some indirect consequences of land use and land cover change through climate change or loss of biodiversity very little attention has been given to the effects of the changes in land use and land cover on human behavior. Indeed, in many societies, particularly in natural resource dependent agrarian societies, changes in land use patterns and land cover have a tremendous impact on social context (Wolman 1993; for details also see Simmons 1987). Thus, changes in land use patterns, particularly at the local community level, may have important consequences for the way individuals' daily social lives are organized in those communities. Sometimes it does not even require changes from one type of land use to another for consequences to be felt. Changes in the way we work with land can bring important changes in society (Foster and Rosenzweig 2003, 2004). Likewise, although major social theories and empirical research suggest important contextual influences on individuals' behaviors (Alexandar 1988; Coleman 1990; Durkheim 1984 [1933]; Fischer 1982; Mills 1959; Smith 1989), very little has been done linking land use to individuals' family behaviors such as their fertility behaviors. Thus, despite the potentially important influence of land use on fertility behavior, contemporary environmental sociologists have yet to enter this promising line of research (Dasgupta 2000).

In this paper we examine this missing, but quite plausible, link between land use and one aspect of fertility behavior, namely first birth timing. Unlike previous studies, we argue that human-land interactions are localized and reciprocally interconnected, therefore, variation in land use at the local community level is likely to have important influences on humans' behaviors, including their fertility behaviors. More specifically, because agricultural activities do not require high skill levels and therefore increase the opportunities for child employment and returns to child labor, individuals living in communities with larger proportions of agricultural land area may be more likely to prefer early childbearing than those from communities that have smaller proportions of land devoted to farming. In contrast, availability of public infrastructure such as schools, roads, and irrigation canals is likely to reduce the opportunity of (and need for) child employment and increase the opportunity costs of childbearing relative to consumption and carrier aspirations. Therefore, individuals from communities with large proportions of the land area devoted to public infrastructure may be less likely to prefer early childbearing than those from communities with smaller proportions devoted to public infrastructure. 
However, because our study setting is predominantly agricultural, we expect to find stronger effects for proportion used for agriculture than for proportion used in public infrastructure.

To execute this study we take advantage of unique data resources from the Chitwan Valley Family Study (CVFS) that are specifically designed to study the reciprocal relationship between population and environment. The Chitwan Valley in central Nepal provides an ideal setting for studying the land use and fertility behavior for several reasons.

First, Nepal, a historically pro-natalist society, is experiencing persistently high population growth and poor economic progress. Although Nepal initiated its antinatalist programs as early as the 1960s, the country has experienced consistently high fertility with a slow rate of fertility decline until very recently (Dongol et al. 1997; Ministry of Health, New Era and ORC Macro 2002; Tuladhar 1989). The Total Fertility Rate (TFR) dropped from 6.3 in 1971 to 4.1 in 2001 and 3.1 in 2006 (Ministry of Health and Population [Nepal], New Era and Macro International 2007).

Second, during the later half of the 20th century, Nepal's landscape has changed dramatically, particularly the conversion of forested land area into agricultural land (Awasthi et al. 2002; FRI 1999; Shrestha 1994, 1999; Tiwari 2000). As early as the 1970s, Erik Eckholm, in his book Losing Ground (1976), vividly presented the condition of deteriorating mountain environments and outlined the consequences of excessive human intervention on the fragile mountain ecosystem (although some think his argument was exaggerated-e.g., Guthman 1997; Ives and Messerli 1989; Karan and Iijima 1985; Metz 1991). Eckholm mentioned that "there is no better place to begin an examination of deteriorating mountain environment than Nepal" (p. 76). He further insists that once the possibility for deforestation for cultivation is exhausted and the hill slopes become nonproductive, the farmers from the hills will become ecological refugees who will then move to the foothills and the piedmont plains. Although Eckholm did not elaborate on what other behavioral changes people may make to adjust to the changes in land use, he indicated migration as an alternative.

Third, despite the fact that the possibility of conversion of forested land into agricultural land in most of the poorer parts of the world is already exhausted, except in Africa and the Brazilian Amazon, most previous studies still focus on the impact of human interventions on conversion of forested land area into cultivable land for food production and do so at a very high level of aggregation, often at a national, regional, or even global level (Enwistle et al. 2003; Goldewijk 2001; Lambin 1997; Lambin et al. 2000; Meyer 1992; Wolman 1993). This study focuses on land use in a settled area and its effects on individual fertility behavior. Thus, this study has direct relevance to many poorer parts of the world where the possibility for conversion of forested land area into cultivable land is already limited.

Finally, the CVFS is ideal for answering questions relating land use and fertility because it provides uniquely detailed measures of land use, first birth timing, individual experiences, household consumption, and local community context collected over a period of time from a single geographical location-the neighborhood. 
We believe that the new knowledge and information this study generates may help planners and policymakers formulate new policies and programs that could help address the country's socioeconomic problems in general and population problems in particular, as well as providing insights into other countries in similar situations.

\section{Theoretical framework}

Ever since Thomas Malthus (1798) first raised concerns regarding population growth outstripping nature's ability to support the growing number of people, this issue has been a central theme of environmental sociologists. Although some of the changes in land use and land cover occur naturally, a large portion of these changes, such as change in percentage of the world land under cultivation, forest, human settlements, and infrastructure, is caused by human action (Liu et al. 2003, 2005; Lutz et al. 2002). It is not surprising to see a growing interest in understanding the relationship between population and land use. As a result, this issue has received much attention and prompted a great deal of research in the later half of the 20th century.

Although Malthus himself indicated a need for individual behavioral change such as self-restraint in timing of marriage and abstinence from sexual activities, most theories and empirical studies done so far have conceptualized population growth as the driving force behind the land use change and the rubric of "population pressure" remained largely dominant in the field (Bilsborrow and DeLargey 1991; Bongaarts 1996; Boserup 1965, 1981; Carr 2004; Cohen 1995; Ehrlich et al. 1993; Fox 1987, 1993; Jolly and Torrey 1993; Malthus 1798; Mortimore 1993; Wolman 1993). This line of argument suggests that as per-unit land area population density increases and the returns to the land per hour worked begin to fall, pressure for the land to provide food and resources for those additional people increases. As a result, the search for higher productivity leads to intensification of land use. Even though Malthus was concerned about both the impact of the growing number of people on the environment and the impact of deteriorating environment on people as well, the rubric of "population pressure" as a cause of environmental degradation became and remained a dominant paradigm in most theories and empirical research throughout the past century. However, drawing on Malthus (1798), Davis (1963), and Boserup's $(1965,1981)$ work, Bilsborrow (1992) suggests that the growing pressure from the increasing number of people on earth leads to a multiphasic response that includes expanding the area under cultivation, reducing fallow time, changing technology, or changes in fertility behavior such as postponing marriage, reducing marital fertility, or out-migration.

Because access to land still continues to be the single most important means of production and livelihood for millions of people in most of the poorer parts of the world, particularly in agrarian societies, it is still an important driving force behind social and economic changes in these societies. Furthermore, as the possibility for conversion of forested land into agricultural land for food production comes close to being exhausted, the relationship between the way the land is being used and social and economic changes has become even more important. 
While impact of population on environment particularly land use has been of interest since Malthus, scholars and policy makers have recently taken increasing interest in the impact of land use on population processes, including individual fertility behavior. One line of such inquiry that links land with individuals' fertility behaviors is limited to the size of the household operational land-holding and land ownership (Cain 1981, 1985, 1986; Stokes et al. 1986; Thomas 1991). Multiple studies in a variety of cultural settings (including Ecuador, Egypt, Iran, Peru and the Philippines) have documented a positive association between land-holding and fertility (Clay and Johnson 1992; Coomes 2001; Easterlin and McCrimmins 1985; Evans and Moran 2002; Good 1980; Hiday 1978; Pichon 1997; Schutjer et al. 1983). This line of inquiry posits two hypotheses: (1) land-security and (2) landlabor demand hypotheses concerning the relationship between household land-holding and marital fertility. The land-security hypothesis presents land as a substitute for children for parental old-age security and suggests a negative relationship between household land ownership and marital fertility (Cain 1981, 1985, 1986; Jensen 1990). Thus, land ownership should reduce the value of children as a source of parental security in old age and therefore lower motivation for additional children. On the other hand, the land-labor demand hypothesis suggests a positive relationship between operational landholding and fertility (Cain 1981, 1985, 1986; Stokes et al. 1986). The size of operational landholding affects fertility by altering the cost-benefit ratio of additional children: The households with access to larger operational landholdings use additional family labor more profitably than those with smaller operational landholding.

These two perspectives have proven useful in thinking about how land might influence human behavior, but for the purpose of this paper, we will focus on land use rather than land ownership. Therefore, to link land use with fertility behaviorin this case, timing of first birth-we draw on one of these two theoretical perspectives, the land-labor demand hypothesis (Cain 1981, 1985, 1986; Stokes et al. 1986; Thomas 1991), in combination with the mode of social organization framework (Thornton and Fricke 1987; Thornton and Lin 1994).

As noted above, the land-labor demand hypothesis, although originally formulated to explain household operational land-holding effects on fertility, essentially suggests that under low mechanization, as the operational land area increases so do the opportunities for child employment and greater returns to the child labor lead to an increased motivation for children. Building on this basic concept we argue that the relationship between operational land area and motivation for children goes beyond the household. We argue that opportunities for child employment are not limited to household operational landholding but also apply to the local community. We expect that because several agricultural activities do not require high skills, living in an agricultural community increases the opportunities for and returns to child labor. Furthermore, as the return to the child labor in an agricultural society increases, it lowers the cost of raising children, leading to increased motivation for children. Thus, we expect that individuals from communities that have more land area under agriculture may be more likely to favor high fertility and consequently have a first birth earlier than those from communities that have less land area used for agriculture. 
The mode of social organization framework, although not explicitly designed to study human-land interactions, also provides a useful theoretical perspective. This framework focuses on the extent to which the activities of daily social life, including production, consumption, socialization, leisure, and reproduction, are organized by the family versus other non-family social institutions and organizations. The key prediction from this perspective is that increased exposure to non-family public social activities among youth will create greater independence between youth and the parental generation (Thornton and Fricke 1987; Thornton and Lin 1994), resulting in the adoption of new family behaviors. In addition, as more public infrastructure is built in the community, the mode of production transfers from a family-oriented subsistence economy to a production-oriented market economy. The economic activities then are likely to provide not only opportunities to participate in those activities, but also to alter individuals' attitudes about social life and social relations within the family. Economic theorists argue that once individuals are exposed to market-oriented production systems, their fertility behaviors are affected through changing costs and benefits of children, women's status, and women's opportunity cost of childbearing (Lobao and Brown 1998; McNicoll 1980; Stokes 1995). Thus, expanding on the mode of social organization framework, we argue that individuals from communities that have more land area used for public infrastructure may be more likely to have first births later than individuals from communities with less area under public infrastructure.

Community context, land use and first birth timing

Although both theories and empirical research suggest an important relationship between land use and fertility, one contentious issue that makes it difficult to assess the impact of land use on fertility, in this case first birth timing, is the fact that local community context likely influences both land use and first birth timing. Previous studies, including work in our study setting, demonstrate important influences of local community characteristics on fertility preference, patterns of consumption, and land use (Axinn and Ghimire 2002; Barber et al. 2003; Biddlecom et al. 2005; McNicoll 2002; Shivakoti et al. 1999; VanLandingham and Hirschman 2001). For example, proximity to an urban center and increased access to non-family services both drive land out of agriculture to other uses (Axinn and Ghimire 2002; Shivakoti et al. 1999).

Likewise, contemporary studies have also shown important contextual influences on family formation and fertility behaviors, including adolescent sexual behavior (Billy et al. 1994; Brewster et al. 1993; Brewster 1994; Brooks-Gunn et al. 1993; Mosher and McNally 1991; Smith 1989; South and Baumer 2000; South and Crowder 2000; Yabiku 2004) family formation, (Hogan and Astone 1986; Lloyd and South 1996; Yabiku 2004), and fertility (Ghimire 2004; Hogan and Kitagawa 1985).

Taken together, this evidence is consistent with the conclusion that the land usefertility relationship is at least partly conditioned by the characteristics of the local community in which individuals live, and therefore it is important to take the 
community context into account. We focus here on five specific community characteristics: size of the neighborhood area, proximity to an urban center, neighborhood wealth, neighborhood electrification, and access to non-family service organizations. These community characteristics are likely to affect the relationship between land use and first birth timing through two important mechanisms: opportunity structures and exposure.

In a predominantly agricultural setting, size of the neighborhood area, proximity to an urban center, neighborhood resources and electrification, and access to nonfamily service organizations such as schools, health services, and wage-labor employers all provide opportunities for activities that compete with farming. For example, larger neighborhood areas may mean more area for agricultural use, on the other hand, proximity to the urban center may promote economic activities that drive individuals out of agriculture. Level of community resources, including electricity, is another crucial factor that may hinder or facilitate economic activities associated with land use. Additionally, access to new non-family service organizations promotes a dramatic reorganization of daily social life (Axinn and Yabiku 2001; Coleman 1990; Thornton and Lin 1994). Increased access to schools, health services, wage-labor employment, markets, and transportation allows individuals to spend more of their daily lives engaged in productive, recreational, consumptive, and other activities away from agriculture. For example, the spread of mass education in this setting dramatically reduced children's time for agricultural activities, thereby severely limiting farm labor.

A growing body of theoretical and empirical work also shows that simple exposure to an urban center or non-family service organization is likely to influence individuals' attitudes and behaviors (Axinn and Yabiku 2001; Barber 2001; Mead 1967). Mead suggests that individuals can develop their "selves" in part by interacting with "others" that are not human. These "others" can be objects that are inanimate (Mead 1967 [1934], p. 154), such as the institutions around them. For example, the presence of an employment center may make an individual see herself or himself as a potential employee. This may then substantially change the views that $\mathrm{s}$ /he holds about the employment center and, at the same time, about non-family work (Barber 2004). In fact, Zajonc (1968) found that the mere presence of a structure might be sufficient to produce a positive attitude toward that structure. This means that having an employment center nearby is likely to produce positive attitudes toward non-family work.

Furthermore, economic theorists argue that the presence of a marketplace with many types of products such as televisions, stereos, motorbikes, cars, air conditioners, freezers, telephones, and, more recently, personal computers, increases preferences for market-produced goods and reduces the relative value placed on childbearing (Blau et al. 1998) and agricultural activities.

Thus, although our main interest is the impact of land use on first birth timing, we examine the impact of local community context to insure variations in that context do not produce a spurious relationship between local land use and first birth timing. This careful consideration of the important effects of community context on both local land use and first birth timing helps to insure the land use effects we observe are reasonable estimates of the true land use effects. 


\section{Setting}

Nepal is widely known both as one of the world's most diverse ecological settings and as a setting on the brink of serious environmental degradation (Blaike and Brookfield 1987; Conway and Shrestha 1981; Eckholm 1976; Fox 1987, 1993; Ives and Messerli 1989; Schmidt-Vogt 1994; Shrestha 1994, 1999; Thapa 1996; Thapa and Paudel 2002; Tiwari 2000). Although the popular perception about Nepal's environmental degradation, first put forward by Eckholm (1976) and later by Ives and Messerli (1989), has not gone unchallenged, the impact of environmental degradation in Nepal's mountains has started taking tolls on Terai area ${ }^{1}$ as early as the 1950s, as they suggested it would. Around the mid-1950s, in order to lessen the impact of rapid population growth on the rather fragile mountain environment, the Nepalese government opened the Terai areas for human settlement as a buffer zone for the rapidly increasing population (Conway and Shrestha 1981; Shrestha et al. 1993). As a result, more than two thirds of Nepal's population now resides and earns their livelihood from $17 \%$ of the land area of the country, that is, in the Terai. While the degradation of mountain environment has not slowed down, the heavy pressure from the population is now affecting the frontier area as well (Dignan 1989; Shrestha 1993; Shrestha et al. 1993; Tiwari 2000).

Chitwan Valley, which was opened for settlement in the early 1950s, lies in the south central part of Nepal and is the study area for this research. Before the 1950s, there were very few human beings in Chitwan except some jungle dwellers who earned their livelihoods by hunting and gathering forest products. As a result, the whole area was covered by dense tropical forest with world famous flora and fauna.

As soon as the area was opened for settlement, the flat terrain with its highly fertile soil and warm climate offered promising opportunities for people who were struggling with the steep mountain slopes to support their survival. Since then, the valley has undergone rapid changes in term of physical, environmental, and socioeconomic conditions (Axinn and Yabiku 2001; Conway and Shrestha 1981; Ghimire and Mohai 2005; Ghimire et al. 2006; Shivakoti et al. 1999; Shrestha et al. 1993). As a result, the dense forest turned into a populated agriculture-based settlement area. Consequently, there has been a dramatic increase in the number of people migrating to the valley and changes in land use. Although change in land use was solely a conversion of dense forest into cultivated land at the beginning, this was completed once the area allocated for settlement was distributed to the people. Once further encroachment was strictly controlled by declaring the rest of forest as National Park and putting armed guards to patrol the boundaries, changes within the settled area became the only reasonable alternative for people to adjust to the changing population.

In late the 1970 s the valley was connected to the rest of the country by a national highway that runs from the east to west of the country. A few years later, another road connected the valley with Kathmandu, the nation's capital. There has been massive expansion of schools, health services, markets, bus stops, and employment centers within the study area. Although the expansion of these services is pervasive,

\footnotetext{
1 Terai is the flat lowland area along the southern border of Nepal.
} 
the level of physical development is still at a very primitive stage. Except the national highway that runs along the northern border of the study area, most of the roads within the study area are seasonal and unpaved. Employment centers are basically service-oriented government agencies and a few agro-based industries. Despite the massive transformation, this valley remains predominantly an agriculture-based society. In fact, $83 \%$ of the households in the study reported that they were growing crops at the time of our survey.

The population of the valley continues to grow both through the constant flow of in migration from the hills and by natural increase. The population in Chitwan is growing at a slightly faster rate than in the rest of the country. The population of the Chitwan district grew from 259,571 to 354,488 between the 1981 and the 1991 censuses. The annual growth of $3.66 \%$ was one of the highest among the various districts of Nepal (Pearce 2000).

With respect to fertility, Nepal has undergone a slow but steady decline until very recently. TFR has declined from 6.3 in 1971 to 4.1 in 2001 and 3.1 in 2006 (HMG/N 2001; Ministry of Health, New Era and ORC Macro 2002; Ministry of Health and Population [Nepal], New Era and Macro International 2007). The average age at first marriage increased from 13.5 years for those who married between 1950 and 1959 to a mean age of 19 years for those who married between 1980 and 1989 (Ghimire 2003; Ghimire et al. 2006; Yabiku 2004). Similarly, the mean age at first birth increased from 18 years for those who first gave birth between 1953 and 1962 to a mean age of 20 for those who first gave birth between 1983 and 1992 (Ghimire 2003). The high fertility rate is associated with young ages at marriage and childbearing (Choe et al. 2001) and low contraceptive prevalence (Satayavada and Adamchak 2000).

The slow pace of fertility decline and the continuous flow of migrants from the hills have kept the growth rate in the Terai areas quite high. Most recent estimates suggest an annual growth rate of 2.37 per annum. The high population growth has increased the pressure on the limited land allowed for settlement and on other natural resources. On the other hand, massive expansion of the infrastructure such as roads, electricity, and canals, along with commercialization in the agricultural sector, has led to diversification of land use. Therefore, the Chitwan valley provides an ideal setting to study the impact of land use on individuals' first birth timing.

Changes in land use within the neighborhood are reflected in the relative magnitude of the land area devoted to different uses. Major changes include a reduction in communal land and forest areas; a shift from relatively low-intensity mono-cropped farming to multiple-cropped, highly intensive farming; and an increase in the land area under residence, private enterprises, and public infrastructure.

\section{Data and methods}

\section{Data}

This study uses multiple data sets collected by the Chitwan Valley Family Study (CVFS) since 1996: neighborhood history calendars, a land use mapping survey, 
household surveys, individual interviews with life history calendars, and a monthly demographic registry and contraceptive survey.

The data to test our hypotheses come from a study of 141 neighborhoods (of 5-15 households each) scattered throughout western Chitwan Valley. These neighborhoods were chosen as an equal probability, systematic sample of neighborhoods in western Chitwan and the characteristics of this sample closely resemble the characteristics of the entire Chitwan Valley (Barber et al. 1997). ${ }^{2}$

Once a neighborhood was selected, a history of that neighborhood was collected using a calendar method (Axinn et al. 1997). Group interviews of people residing in and near the neighborhood were conducted to generate information on changes in neighborhood services and facilities from 1953 to 1995. Furthermore, the information collected on neighborhood services from these interviews was verified with archival records from local institutions such as schools, health services, and district-level government offices.

Simultaneously, CVFS gathered information on land area under different uses in those neighborhoods beginning in 1996. A team of field workers physically mapped every square foot of the land area of each neighborhood using compasses and tape measures. These measurements were computerized and used to calculate the land area of each neighborhood by land use type.

Following the neighborhood land-use mapping, household surveys were carried out to collect information pertaining to household resources in 1996. The household survey collected information about household economic status, including farming (crops grown, mechanization, landholdings), livestock (number, management, feeding practices), household possessions, and housing quality.

After the household surveys were conducted, all individuals aged 15 to 59 residing in the sampled households were personally interviewed using a standardized questionnaire and a life history calendar (LHC). Respondents' spouses were also interviewed, even if they lived elsewhere or were outside the age range. In the standardized interviews, individuals were asked a variety of questions regarding their family backgrounds, personal characteristics, experiences, childhood community contexts, and attitudes about various aspects of social life. In addition, the LHC portion of the survey collected information on residence, marital status, children, contraceptive use, living arrangements, schooling, and work experience. The LHC provides special advantages for accurate retrospective measurement and sequencing of personal life events (Axinn et al. 1999; Belli 1998; Freedman et al. 1988), and the structured interview allows these reported events to be linked to personal and contextual characteristics.

Finally, the CVFS gathered information on first birth and contraceptive use through a monthly demographic and contraceptive use survey. After the individual

\footnotetext{
${ }^{2}$ Boundaries of the land surrounding these neighborhoods bisect the areas between the selected neighborhoods and adjoining neighborhoods. This boundary procedure gives every unit of land in Chitwan one and only one chance of falling into our sample. This procedure also means neighborhoods in more densely settled areas are characterized by smaller land areas than neighborhoods in more sparsely settled areas. Therefore we always take total land area into account when constructing our measures of land use. However, our sampling procedures produce a sample of the population of western Chitwan and the land associated with the population sample. Our procedures are not designed to produce a representative sample of the land in western Chitwan.
} 
interviews ended in 1997, the CVFS started collecting information each month from the respondent households on demographic events including migration, living arrangements, marriages, births, and deaths. Also, all individuals interviewed in 1996 who were not sterilized at that time were visited once every 3 months and asked about personal contraceptive use during the previous 3 months. If any original households or respondents moved out of the sample neighborhood, they were followed, and new households and respondents who moved into the sample neighborhoods were added to the monthly registry system. This study uses 72 months of monthly data from the demographic and contraceptive use registry.

From the CVFS data, we use a sample of women aged 15-29 in 1996 who had not previously given birth and who were neither sterilized nor married to men who were sterilized. The resulting sample included 380 married women. Because the outcome (first birth) is measured prospectively we are able to use all the measures of the land use, neighborhood characteristics, and respondents' experiences as predictors. In addition, the prospective measurement also allows us to use the measures of intervening factors: marriage duration, and contraceptive use.

\section{Measures of first birth timing}

Our analyses focus on first birth timing. Because the decision about and risk of having a first child is generally resolved upon conception, we use the timing of pregnancy that resulted in live birth rather than birth itself as the dependent variable. ${ }^{3}$ From the household registry, which provides monthly records of first births, we calculate the occurrence of pregnancy ( 9 months prior to childbirth) and construct a person-month measure of the occurrence of pregnancy that serves as the unit of analysis in this study. This practice has been used successfully in previous research (Axinn and Yabiku 2001; Barber 2001). We create person-month data files from this information by coding the dependent variable " 0 " in all periods before the respondent becomes pregnant and " 1 " in the month she becomes pregnant. Once a pregnancy has occurred, the respondent is censored from the analysis. Individuals who did not become pregnant during the observation period are censored at the end of this period.

\section{Measures of land use}

Our measures of land use come from the land use mapping survey. Each piece of land measured was categorized into distinct categories that best describe the type of

\footnotetext{
3 Although using only the pregnancies that resulted in live births results is likely to under report the total number of pregnancies, this strategy was chosen because: (1) induced abortion is not common, although it has been legalized recently (the estimate based on the 2001 Nepal DHS data indicates that induced abortions account for .6\% of pregnancies in rural areas of Nepal (Ministry of Health [Nepal] 2002)), (2) the measures of miscarriage and stillbirth are subject to misreporting, and (3) the pregnancies that resulted in live births were accurately measured and are of our greatest interest. Furthermore, the estimate based on the 2001 Nepal DHS data indicates that induced abortions account for $.6 \%$ of pregnancies in rural areas of Nepal (Ministry of Health [Nepal] 2002).
} 
land use. These measurements were then computerized and used to calculate the land area under each specific land use. Major categories of land use consist of agricultural land basically used for cultivation of crops; forest land used to collect timber, fuelwood, and fodder; common land used for livestock grazing and used as open space for other community activities, such as playgrounds for children and communal ceremonies; and land with other uses such as roads, irrigation canals, and temples.

In our analyses we use these data to construct two specific measures of land use: percentage of neighborhood land area (1) under agriculture and, (2) under public infrastructure. The measure of agricultural land is the fraction of total land area devoted to crop cultivation that includes both upland and irrigated and non-irrigated lowland. This land is primarily used for food production. The measure of land area under public infrastructure is the fraction of total land area devoted to public infrastructure such as schools, roads, canals, mills, temples, and other buildings.

\section{Measures of community characteristics}

Measures of community characteristics include neighborhood size, neighborhood wealth, neighborhood electrification, and proximity to non-family service organizations and the urban center from the respondent's place of residence.

\section{Neighborhood size}

Our measure of neighborhood size comes from the land use mapping survey conducted in 1996. The total area of each neighborhood equals the sum of the individual land parcels that are under different uses within the boundaries of that neighborhood. The total land area measured in square feet is then converted into square miles.

\section{Distance to urban center}

The measure of distance to the urban center (Narayanghat) is garnered from the neighborhood history data and checked using maps of the valley and a Geographic Information System (GIS). The exact latitude and longitude location of each neighborhood, ascertained from 1:25,000 maps based on aerial photographs of the valley, were entered into a GIS that calculated the distance between each neighborhood and Narayanghat, the valley's only urban center. This measure is coded in miles.

\section{Neighborhood wealth}

Our measures of wealth come from household interviews which included a series of questions about different sources of household wealth, such as whether the 
household owned the house plot or any farm land, the number of farm animals owned, the number of pieces of farm and household equipment owned, and housing quality. While the measures of ownership of house plot, farm land, livestock, number of farm parcels, and household equipment come from the responses to the household survey itself, the measure of housing quality comes from interviewers' observations. Because the scale of responses to each of the questions varies, we standardized the values in each of these domains into Z-scores (mean of 0 and standard deviation of 1) and summed them to construct a composite index of household wealth. This household index was then averaged to create a neighborhood-level measure of wealth.

\section{Neighborhood electrification}

Neighborhood electrification is a measure of whether the neighborhood has electricity. Our measure of neighborhood electrification comes from neighborhood history calendar and is coded as " 1 " if the neighborhood has electricity and " 0 " otherwise.

\section{Non-family service organizations}

The neighborhood history data also provide measures of distance in walking time from the respondent's current neighborhood to the nearest school, health service, bus stop, employment center, and market. These data provide dynamic measures of how far away each service was from the neighborhood for each year from 1953 to 1995 (Axinn et al. 1997). These walking times vary from 0 min (when the service is located within the neighborhood) to hundreds of minutes (a couple of days walk from the neighborhood). We create dummy variables for each of the five services indicating whether the nearest service location was within a 15-min walk of the respondent's neighborhood in a specific year. ${ }^{4}$ We then sum these responses for the total number of years a certain service was within a 15-min walking distance. Finally, we construct a composite neighborhood index by summing the responses from each of the five services and dividing by the number of services. This coding system has been successfully used in previous studies (Axinn and Yabiku 2001; Yabiku 2004).

\section{Measures of controls}

The controls include respondent characteristics and experiences and parental experiences.

\footnotetext{
${ }^{4}$ Because of the potential overlap with the measure of land used for infrastructure, we do not include the non-family service organizations that are actually within the neighborhood to calculate this measure.
} 


\section{Respondents' characteristics and experiences}

The measures of respondents' characteristics and experiences come from 1996 individual interview and life history calendar interview and include: age in 1996, ethnicity, marital experience, schooling, employment, and exposure to media.

\section{Ethnicity}

Previous research in Chitwan suggests a strong effect of ethnicity on fertility intentions (Pearce 2000) and family formation behaviors (Axinn and Barber 2001; Ghimire et al. Forthcoming; Thapa 1989, 1997). Nepalese society consists of many ethnic and linguistic subgroups (Bista 1972; Dahal 1993; Gurung 1980, 1998). Although ethnicity in Nepal is complex, scholars have often categorized ethnicity into five major groups for analytical purposes: High Caste Hindus, Low Caste Hindus, Newar, Hill Tibeto-burmese, and Terai Tibeto-burmese (Axinn and Yabiku 2001; Blaikie et al. 1980). We have adopted these categories for our analyses. For more information about these ethnic groups see Bista (1972), Gurung (1980), and Fricke (1988). We coded individuals " 1 " if they are members of a specific category and " 0 " if not, using High Caste Hindus as the reference group for comparison.

\section{Marital experiences}

Marriage is still the principle route to exposure to sexual intercourse in Chitwan. Thus a respondent's marital experiences have a strong association with the propensity for conception and pregnancy. Respondents' marital experiences include age at first marriage (coded in years) and duration of marriage (coded as number of months). Because respondents are married at different times, some even before the start of the hazard and others during the observation period, we separate the marriage duration into two measures: marriage duration before 1997 and during the observation period. We coded marriage duration before 1997 in number of months and treated it as a control. Because the marriage duration during the observation period also represents the hazard duration, we included it as a hazard function. We coded the marriage duration during the observation (after 1997) as a series of dummy variables in 6-month increments $(1-6,7-12 \ldots 42+$ months) and treated " $42+$ months" as the reference group.

\section{Educational attainment}

The CVFS collected a complete history of respondents' educational experiences, including adult education (literacy programs), via the life history calendar. This record provides information on the total length of time spent in school and adult literacy classes. Using the total number of years respondents spent in school or adult education, we constructed a series of dummy variables, "0-3," "4-7," "8-11," and 
"12 or more" years of schooling, and treated "0-3 years of schooling" as the reference group.

\section{Employment}

Our measure of employment also uses information from the LHC. All years that a respondent was employed outside the family were recorded and from this we created a total number of years of employment.

\section{Media exposure}

Our measure of media exposure is an index constructed from responses to three sets of questions in the individual interview. Respondents were asked, "Have you ever listened to a radio?" Similar questions were asked about watching television and seeing movies. We coded each item " 1 " if the respondent had been exposed to radio, television, or movies before marriage and " 0 " otherwise. Because responses to these questions are correlated, in order to avoid problems of multicollinearity, we sum these three variables into a scale with values ranging from zero (not exposed to any media source prior to marriage) to three (exposed to all three sources).

\section{Contraceptive use}

The measure of contraceptive use comes from the monthly prospective family planning survey and is coded " 1 " if a woman has used any modern contraceptive method (pills, condom, IUD, depo-provera, sterilization, etc.) during that period and " 0 " otherwise. Thus, contraceptive use is also a time-varying dichotomous variable.

\section{Parental experiences}

Because parental experiences may affect both children's experiences and their first birth timing, we control for a number of parental characteristics in our multivariate models. These include: mother's total number of children, education, and work; father's education and work; and parents' contraceptive use. These measures are derived from the respondent's answers to a series of questions about her parents, for example: "How many children did your mother have?" or "Did your mother ever go to school?" All responses except number of children, which is coded in actual number of children ever born, were coded dichotomously, using " 1 " for "yes" and " 0 " for "no."

\section{Analytical strategy}

We use a three-step analytical strategy to estimate the effects of land use on first birth timing, or the rate of first birth during the observation period. First, we 
estimate the total effects of land area under specific use (agriculture or public infrastructure) with some basic controls. Second, we add the measures of community characteristics into the model. Finally, we add the measures of respondents' non-family experiences and proximate determinants, the intervening experiences, into the model. With regard to temporal ordering, the measures of land use, neighborhood characteristics, and respondents' experiences were all measured during 1995 and 1996, about a year before the observation period for the first birth timing starts. Thus, our analytical approach is guided by the argument that neighborhood land use affects first birth timing through respondents' experiences and the proximate determinants of fertility.

We estimate discrete-time hazard models using a standard logistic regression procedure. ${ }^{5}$ Logistic regression is an appropriate statistical technique for analyzing multivariate models of dichotomous dependent variables (Kmenta 1986). Although using the person-period of exposure to risk as the unit of analysis substantially increases the sample size, Allison (1982, 1995) and Petersen (1991) have demonstrated that using discrete-time methods does not deflate the standard errors and that these methods provide appropriate tests of statistical significance.

The interpretation of the estimates of parameter effects is not as intuitive as a simple percent change. Therefore, in order to make the interpretation of the results more intuitive, we exponentiate the raw log-odds coefficients. Because we use logistic regression, the exponentiated coefficient specifies the effects on the odds of experiencing a first birth in the period of analysis. The odds of an event occurring versus not occurring in a given period are $P /(1-P)$, where $P$ is the probability of the event occurring. We discuss the results as odds ratios, which is the anti-log of the coefficient. These odds ratios can be interpreted as the amount by which the odds are multiplied for each unit change in the respective independent variable. That

\footnotetext{
5 There are two basic concerns when using the discrete-time event history models: first, when to start the hazard, and second what functional form for duration of the hazard to use. The start of the hazard should begin when the respondents become at risk of the event. In principle, a woman is at risk of giving birth to a baby when she has sexual intercourse with a man, provided that she is biologically fecund. However, in Nepal, premarital sex is very much discouraged socially and in most cases sexual activities of women usually take place only within marriage. In fact, there is almost no premarital birth in Nepal (Retherford and Thapa 1998) therefore, we start the hazard at marriage. However, starting the hazard at marriage raises two issues. First, on the one hand, starting the hazard at marriage will exclude all unmarried women from the analyses and we will not be able to estimate the influence of neighborhood land use on first birth timing that works via timing of marriage. On the other hand, including unmarried makes no sense when there is almost no premarital birth. Our ethnographic work shows that out of 1,000 unmarried women in our sample, only eight women experienced pre-marital conception, who then got married before giving birth. Next, these women married at different points in time, some were married before the start of the observation period (1997) others married during the observation period. This introduces complication in parameterization of duration in terms of time. To address this issue we treat the duration of marriage before the start of the observation period (1997) and age at marriage as controls and included the time during the observation period as hazard duration in our models. Second, the functional form of the hazard duration. In our models, we have parameterized the duration of hazard as series of dummy variables in 6month increments. This allows the risk of having a first birth to vary by 6 months. As most women in Nepal get pregnant soon after their marriages, mostly within 18 months of their marriage, this functional form is an appropriate approximation for first birth timing in Nepal. However, we also tested for other functional forms: log function, linear function, and quadratic function, but the results only vary slightly. Therefore, based on the model fit criterion, we chose the 6-month dummies as an appropriate functional form of the hazard duration.
} 
means that if the odds ratio is greater than 1, the effect is positive and every unit change in the independent variable increases the odds of first birth. If the odds ratio is less than 1, every unit change in the independent variable decreases the odds of first birth. Moreover, these ratios can be easily transformed into percent change in the odds associated with each unit change in respective independent variable by subtracting 1 from the odds ratio and multiplying by 100 (Axinn and Yabiku 2001). For example, an odds multiplier of 1.009 for land area under agriculture suggests that those women who live in a neighborhood with $10 \%$ of land area devoted to agriculture are $9 \%$ more likely $\left(1.009^{10}=1.09 ; 1.09-1.00=.09\right)$ to experience a first birth than their peers who live in neighborhoods with no land under agriculture. In addition, when the size of the risk set is large and the number of events in a time interval is small, the odds converge on the rates. In our models of first birth timing, the number of first births occurring in each month is small relative to the number of individuals at risk; for parsimony we refer to the odds as rates.

\section{Results}

The results are presented in the order outlined in the theoretical framework and we present the results of agricultural land followed by public infrastructure. However, before moving into the details of our multivariate analyses we first briefly discuss some descriptive statistics.

\section{Descriptive statistics}

Table 1 presents the means, standard deviations, and the minimum and maximum values for the measures of land use, community characteristics, respondents' parents' experiences, and respondents' own characteristics and experiences. ${ }^{6}$

The mean of 71.28 (range of 0-94.17) for percent of land area under agricultural uses indicates that more than two thirds of neighborhood land is devoted to agriculture. In contrast, a mean of 9.32 (range of 1.07-45.57) for percent land are under public infrastructure indicates that slightly less than $10 \%$ of neighborhood land area is devoted to public infrastructure including schools, temples, mills, other buildings, roads, and canals. Although our sample neighborhoods are largely agricultural, the ranges for both agricultural land and land area under public infrastructure suggest great variability within these neighborhoods.

Similar variations are observable in other community characteristics. The neighborhood land area varies from .003 to .116 square miles with a mean of .03 square miles, a relatively small neighborhood. The distance to the urban center varies from .02 to 17.70 miles with a mean of 8.69 miles. The neighborhood wealth index ranges from -2.82 to 41.57 with a mean of .32 . Out of 141 neighborhoods

\footnotetext{
${ }^{6}$ Because some of the variables are time-varying and change over the duration of hazard, we have to choose a time point at which to summarize these values. Here we have chosen the value in the last observed time unit (month) for the individuals who gave birth. For others who did not give birth during the observation period, it is the value at the end of the observation period.
} 
Table 1 Descriptive statistics for measures used in analyses $(\mathrm{N}=380)$

Independent variables Coding Mean Std. Dev. Min. Max.

\section{Land use}

Area under agriculture

Area under public infrastructure

Community characteristics

Neighborhood wealth

Distance to urban center

Non-family services within a 15-min walk

Neighborhood area

Electricity in 1996

Controls

Respondent's parents' experiences

Mother's number of children

Mother worked for pay

Mother's education

Father's education

Father worked for pay

Parents' contraceptive use

Respondent's characteristics

\section{Ethnicity}

High Caste Hindu

Low Caste Hindu

Newar

Hill Tibeto-brumese

Terai Tibeto-burmese

Age

Age in 1996

Years

Years

Months

Index

Miles

Marriage

Age at first marriage

Marriage duration before 1997
Percent land area

Percent land area

\# of years of services

Square mile

$0=$ No, 1 = Yes

Numbers

$0=$ No, $1=$ Yes

$0=$ No, $1=$ Yes

$0=$ No, $1=$ Yes

$0=$ No, $1=$ Yes

$0=$ No, $1=$ Yes

$0=$ No, $1=$ Yes

$0=\mathrm{No}, 1=$ Yes

$0=$ No, $1=$ Yes

$0=$ No, 1 = Yes

$0=$ No, $1=$ Yes

Marriage duration during observation period

Married for 1-6 months

Married for 7-12 months

Married for 13-18 months

Married for 19-24 months

Married for 25-30 months

Married for 31-36 months

Married for 37-42 months

Married for more than 42 months

$$
\begin{aligned}
& 0=\text { No, } 1=\text { Yes } \\
& 0=\text { No, } 1=\text { Yes } \\
& 0=\text { No, } 1=\text { Yes } \\
& 0=\text { No, } 1=\text { Yes } \\
& 0=\text { No, } 1=\text { Yes } \\
& 0=\text { No, } 1=\text { Yes } \\
& 0=\text { No, } 1=\text { Yes } \\
& 0=\text { No, } 1=\text { Yes }
\end{aligned}
$$

$\begin{array}{rr}71.28 & 21.99\end{array}$

$9.32 \quad 7.55$

000

94.17

$\begin{array}{rr}.32 & 4.02 \\ 8.69 & 4.01\end{array}$

$17.28 \quad 9.38$

$.00 \quad 41.60$

.003

.116

$.00 \quad 1.00$

$.37 \quad .48$

$\begin{array}{ll}5.39 & 2.12\end{array}$

$1.00 \quad 14.00$

$.21 \quad .41$

$.00 \quad 1.00$

$.00 \quad 1.00$

$.00 \quad 1.00$

$.00 \quad 1.00$

$.00 \quad 1.00$

$\begin{array}{rrcr}.52 & .50 & .00 & 1.00 \\ .09 & .29 & .00 & 1.00 \\ .08 & .27 & 0 & 1.00 \\ .15 & .35 & 0 & 1.00 \\ .16 & .40 & 0 & 1.00 \\ & & & \\ 18.05 & 2.62 & 15 & 29.00 \\ & & & \\ 19.63 & 3.07 & 13 & 31.00 \\ 7.17 & 14.70 & 0 & 66.00\end{array}$

$\begin{array}{llll}.41 & .49 & .00 & 1.00 \\ .20 & .40 & .00 & 1.00 \\ .13 & .33 & .00 & 1.00 \\ .06 & .24 & .00 & 1.00 \\ .03 & .18 & .00 & 1.00 \\ .03 & .18 & .00 & 1.00 \\ .03 & .17 & .00 & 1.00 \\ .11 & .31 & .00 & 1.00\end{array}$


Table 1 continued

\begin{tabular}{|c|c|c|c|c|c|}
\hline Independent variables & Coding & Mean & Std. Dev. & Min. & Max. \\
\hline \multicolumn{6}{|l|}{ Respondent's non-family experiences } \\
\hline \multicolumn{6}{|l|}{ Educational attainment } \\
\hline $0-3$ years of schooling & $0=$ No, $1=$ Yes & .16 & .37 & .00 & 1.00 \\
\hline 4-7 years of schooling & $0=$ No, $1=$ Yes & .10 & .30 & .00 & 1.00 \\
\hline $8-11$ years of schooling & $0=$ No, $1=$ Yes & .36 & .48 & .00 & 1.00 \\
\hline 12 or more years of schooling & $0=$ No, $1=$ Yes & .38 & .49 & .00 & 1.00 \\
\hline \multicolumn{6}{|l|}{ Employment } \\
\hline Years worked outside of home for pay & Years & 1.94 & 2.59 & .00 & 14.00 \\
\hline \multicolumn{6}{|l|}{ Media exposure } \\
\hline $\begin{array}{l}\text { Exposure to media sources before } \\
\text { marriage }\end{array}$ & Index $(0-3)$ & 2.84 & .43 & .00 & 3.00 \\
\hline \multicolumn{6}{|l|}{ Contraceptive use } \\
\hline $\begin{array}{l}\text { Used contraceptive last month } \\
\text { (time varying) }\end{array}$ & $0=$ No, $1=$ Yes & .03 & .16 & .00 & 1.00 \\
\hline
\end{tabular}

only $37 \%$ of the neighborhoods have electricity. In terms of access to non-family services, on average, sample neighborhoods have had non-family service organizations (school, health service, bus stop, employment center, or market) within a 15min walk for almost 15 years. However, the minimum value of 0 suggests that there are also neighborhoods that have never had any of the services within 15 min walk. This means the young women in Chitwan are exposed to diverse social conditions, depending on where they reside.

In terms of respondents' family background, our sample came from families of high maternal fertility, a mean of 5.39 children per mother, a large gender gap in terms of mothers' and fathers' education and non-family employment, and moderately high levels of contraceptive use by parents. With respect to the ethnic distribution, slightly more half (52\%) of the population are High Caste Hindus, followed by $16 \%$ Terai Tibeto-burmese (believed to be indigenous to Chitwan), 15\% Hill Tibeto-burmese, $8 \%$ Newar, and 9\% Low Caste Hindus.

Our sample has a mean age of 18.05 at the beginning of the observation period (1996) with a mean age at first marriage of 19.63 . Those who were married before 1997 were on average married for 7.17 months. More than half of the sample was married less than a year. Out of 380 women, 304 women gave birth to their first baby by the end of the observation period. More than half (62\%) of the respondents have less than 12 years of schooling. The sample has a mean of 1.94 years for nonfamily employment but a very high level of media exposure with a mean of 2.84 on a scale of zero to three. The duration between marriage and first pregnancy lasted about a year, and half of the women were living with their husbands at the end of observation period. A very small part of the sample, only 3\%, had ever used contraceptives. With this background information we now move to the results of our multivariate analyses. 
Multivariate analyses

Table 2 presents the results of our multivariate models of neighborhood land area under agriculture and under public infrastructure.

\section{Models of land area under agriculture}

Panel A in Table 2 presents the impact of the percent land area under agricultural uses on first birth timing. First, in Model 1, we estimate the impact of agricultural land area on first birth timing with some basic controls. Our strategy of estimating the impact of area used for agriculture with only basic controls is guided by the assumption that the neighborhood land use is exogenous to other neighborhood characteristics and respondent experiences.

In our models of land use and first birth timing we controlled for respondents' family background, ethnicity, marital experiences (age at marriage and marriage duration), and hazard duration. As shown in Model 1 of Table 2, a respondent's family background, ethnicity, and marital experience each have a statistically significant effect on the rate of first birth. The odds ratio of .95 for mother's number of children suggests that every additional sibling lowers the rates of first birth by 5\%. That means those whose mother has 5 children (respondent's siblings) are likely to experience first birth at rates $9 \%$ lower than those whose mother has only 3 children. This finding is consistent with idea that daughters who have seen their mother gone through the pain of multiple pregnancies and poor health condition are more likely to postpone pregnancy until they are fully matured and can fully understand the consequences. Similarly, father's work and parents' contraceptive use have strong negative, statistically significant effects on the rates of first birth.

Similarly, respondents' characteristics and experiences also have important influences on the rate of first birth. For example, ethnic background: While Low Caste Hindus and Hill Tibeto-burmese are likely to experience first birth at much lower rates than High Caste Hindus, Newars and Terai Tibeto-burmese do not experience first births at rates significantly different from the High Caste Hindus. Although age at marriage and marital duration both affect the rate of first birth, only the effect of marital duration is statistically significant. We found that marital duration has a strong negative, statistically significant impact on first birth timing. The odds ratio of .98 for marital duration before 1997 suggests that each additional month of marriage duration decreases the rates of first birth by $2 \%$. That means those women who are married for 10 months before 1997 are likely to experience first birth in any given month at rates $24 \%$ lower than those who were just married. This is likely because, in non-industrialized settings such as Nepal where there are strong social taboos on childlessness, newly married women make every effort to get pregnant as soon as possible after their marriage (Acharya 1998; Acharya and Bennett 1981; Bennett 1983; Stone 1978; Suwal 2001). Thus, most fecund women are likely to get pregnant soon after their marriage and the women who have been married longer would be less likely to experience a first birth because they have crossed this initial period. Likewise, the odds ratio of 2.59 for 1-6 months of 


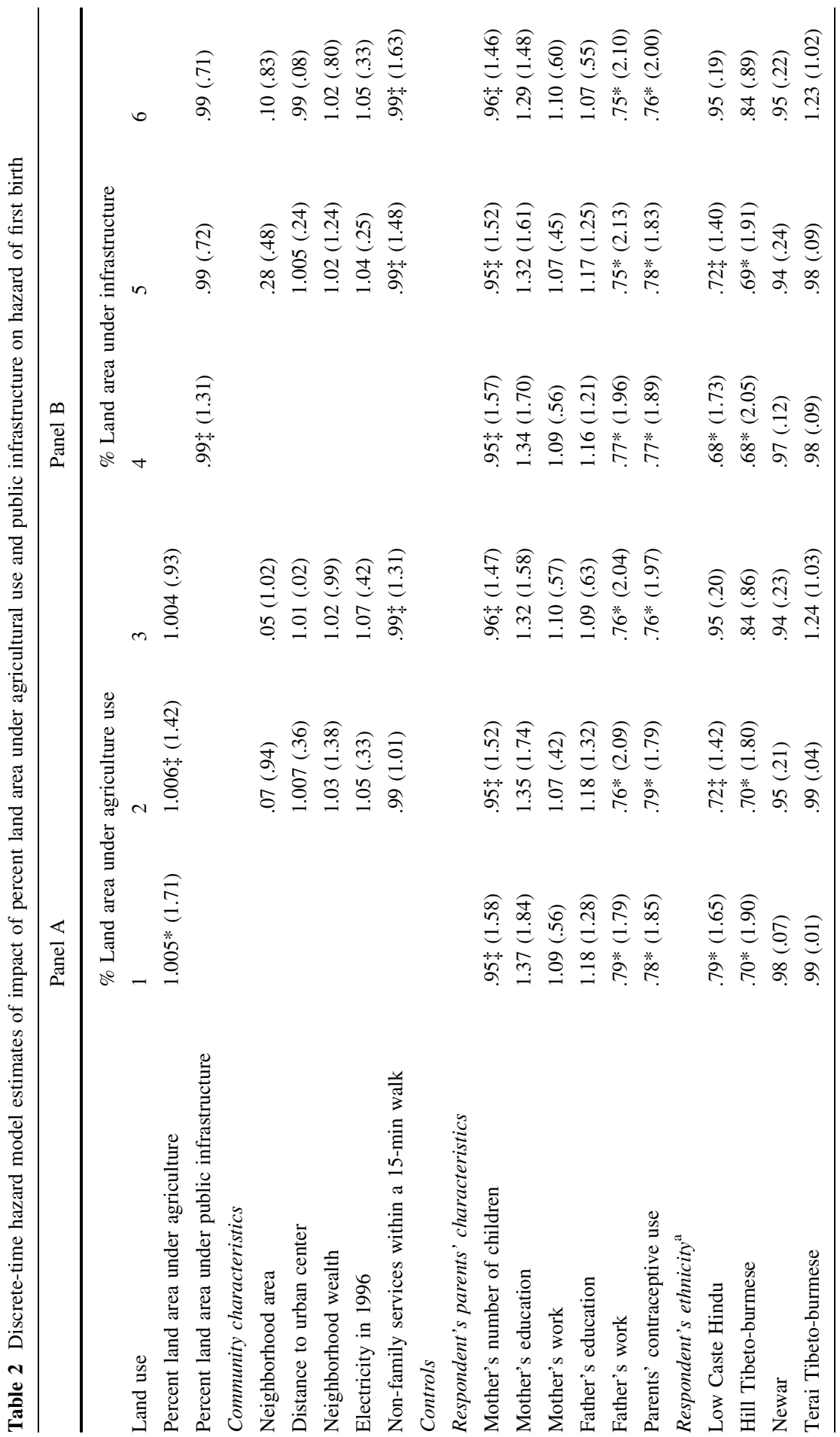




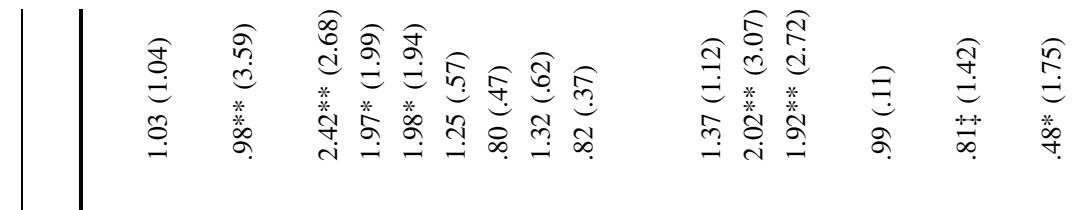

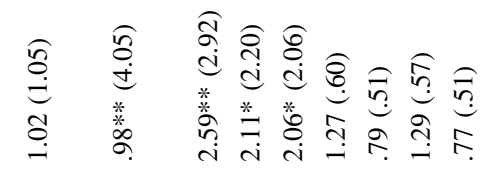

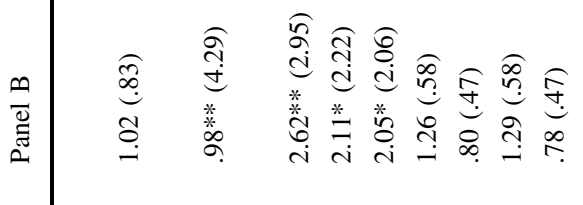

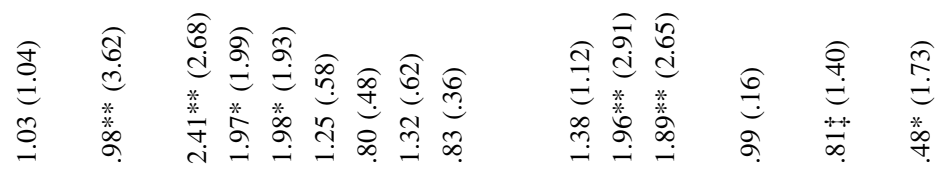

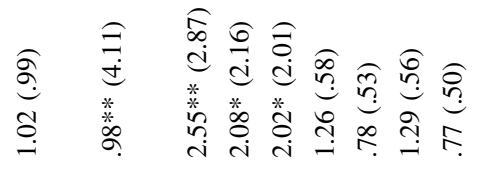

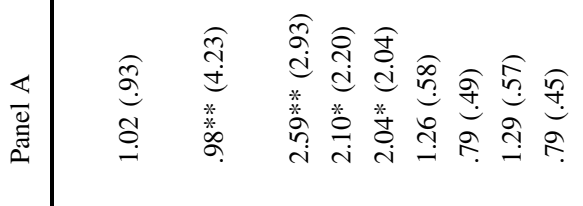

$$
\begin{aligned}
& \text { ะี้ } \\
& \text { (ำ }
\end{aligned}
$$

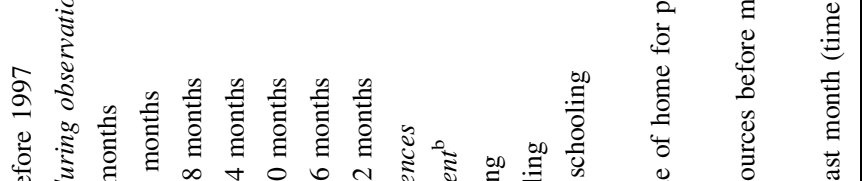

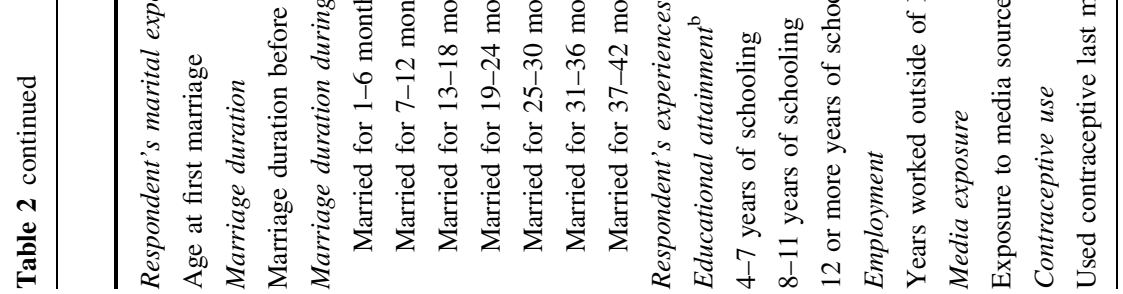




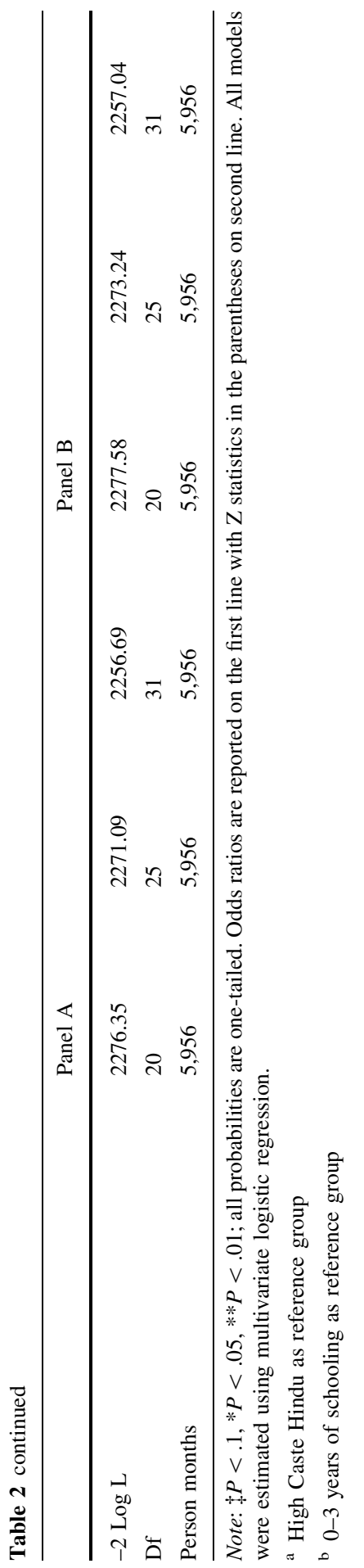


marriage duration during observation period suggests that those who were married for 1-6 months have a first birth at rates $159 \%$ higher than those who were married for more than 42 months.

Total effects of land area under agriculture: The estimates of the impact of agricultural land on the rate of first birth indicate that percent of agricultural land has a strong positive, statistically significant effect on first birth timing, as we expected. The odds multiplier of 1.005 indicates $1 \%$ increase in agricultural land increases the rate of first birth by a little more than one twentieth of one percent. Although this seems trivial at face value, because the percent of agricultural land ranges from 0 to 94 , this is an enormous impact in its potential. This means women who live in a neighborhood that is $50 \%$ agricultural experience first birth at rates $28 \%$ higher $\left(1.005^{50}=1.28 ; 1.28-1.00=.28\right)$ than their peers who live in a neighborhood with no agricultural land. This is truly a large effect.

Effect of land area under agriculture independent of community characteristics: In Model 2 (also shown in Table 2) we add the community characteristics: neighborhood land area, distance to the urban center, neighborhood wealth, neighborhood electrification, and the mean number of years there have been non-family services within a 15-min walk from the respondent's current neighborhood. None of the five neighborhood characteristics has an independent statistically significant effect on the rate of first birth. The size of the odds ratio for land area under agriculture remained the same suggesting that the effect of land area under agriculture is independent of the community characteristics we included in our models. However, now the effect of neighborhood land area under agriculture is statistically significant only at $P=.10$ level of significance.

Respondents' experiences: In Model 3 we added respondents' experiences with schooling, employment, media exposure, and contraceptive use to Model 2. We found that respondents' educational attainment has a strong positive, statistically significant impact on the rate of first birth. Those women who had more than 3 years of education experienced their first birth at much higher rates than those who have 3 or fewer years of education. Although the positive association between education and fertility is a little surprising, this finding is consistent with the findings of previous studies that separate education into attainment and enrollment (Ghimire 2003; Suwal 2001; Thornton et al. 1995; Yabiku 2004) and with the human capital hypothesis which says that the more knowledge and skills individuals acquired through education, the more prepared they are to take on higher roles such as parenthood. The effect of employment was statistically significant in separate models (not shown in the table) but is not significant here. However, media exposure has a strong negative, statistically significant effect on the rate of first birth as expected. The odds multiplier of .81 suggests respondents who were exposed to at least one source of media are likely to experience first birth at rates $19 \%$ lower than those who have not been exposed to any media before their marriages.

In terms of respondents' contraceptive use experience, contraceptive use reduces the rate of first birth by more than half, also as expected. The odds multiplier of .48 suggests those who used contraceptives experienced first birth at rates $52 \%$ lower than those who did not use contraceptives. Considering the social pressure for giving birth soon after marriage, this is an enormous effect. 
Moreover, when measures of respondents' non-family experiences and contraceptive use were added to model 2 , the odds ratio for land area under agriculture was reduced from 1.005 to 1.004 and became statistically insignificant. This suggests that the effect of agricultural land works through respondents' non-family experiences and contraceptive use. This finding is consistent with our theoretical assumption that individuals' experiences are exogenous to neighborhood land use. It is also consistent with the proximate determinants of fertility framework that suggests that any socioeconomic, cultural, and environmental factors should affect fertility only through proximate determinants (Bongaarts 1978).

\section{Models of land area under public infrastructure}

Following the same strategy, in Panel B of Table 2 we present the estimates of the effects of neighborhood land area under public infrastructure. Because the effects of controls are very similar to those of Model 1 (Panel A) in Table 2, for the sake of parsimony, we will not repeat the discussion here.

Total effects of land area under public infrastructures: Model 4 in Panel B of Table 2 presents the effect of neighborhood land area devoted to public infrastructure on the rate of first birth. The estimates of the impact of land area under public infrastructure indicate that percent of land area under public infrastructure has a negative, statistically significant (at $P=.10$ ) effect on first birth timing, as expected. The odds multiplier of .99 indicates $1 \%$ increase in land for public infrastructure reduces the rate of first birth by $1 \%$. This means women who live in a neighborhood with only $10 \%$ of its land area devoted to public infrastructure experience first birth at rates $9 \%$ lower than their peers who live in neighborhoods with no land under public infrastructure, again an enormous cumulative impact.

Effect of land area under public infrastructure independent of community characteristics: Next, we added community characteristics to Model 4, resulting in Model 5. Of the five community characteristics, only access to non-family services has a statistically significant effect. The odds ratio of .99 for the average number of years non-family services existed within a 15-min walk from the respondent's neighborhood suggests that each additional year of having the non-family services within a 15 -min walk reduces the rate of first birth by $1 \%$. Thus, those who lived in a neighborhood that has had non-family services within a 15-min walk for 15 years experienced first birth at rates $15 \%$ lower than those who live in neighborhoods that still have no non-family services within a 15-min walk. Moreover, when neighborhood characteristics were added to Model 4, although the odds ratio for the land area under public infrastructure remained unchanged, it became statistically insignificant, suggesting that the effects of land area under public infrastructure work through the non-family services around the neighborhood.

Respondents' experiences: Finally, in Model 6 we added respondents' experiences into Model 5. We found that the effects of respondents' experiences closely resemble the results of Model 3 (Panel A) of Table 2. Thus, for parsimony we again do not repeat the discussion of these effects here. 


\section{Conclusions}

In this paper, we began by reorienting the popular notion of the impact of population pressure on the earth's resources to thinking about the impact of land use at a community level on individuals' fertility, with the aim of generating new insight into reciprocal relationships between population and environment. We focused on two specific dimensions of land use: the percent of the land area under agriculture and the percent of the land area used for public infrastructure. We hypothesize that higher proportions of agricultural land should motivate young women for early childbearing through higher returns to child labor. On the contrary, a higher proportion of neighborhood land area used for public infrastructure should encourage delayed childbearing through changes in achievement aspirations and attitudes toward family life and non-family activities. The findings of this study provide empirical evidence about several of the relationships between land use and first birth timing and generate a number of new questions at the same time.

Findings of these analyses support our hypothesis that living in neighborhoods with large proportions of land devoted to agriculture encourages early childbearing. Although this is an important finding in itself, the more interesting result is the fact that this effect is net of community characteristics such as neighborhood land area, neighborhood wealth, distance to the urban center, electrification, and access to nonfamily service organizations. This suggests that, despite the competing influences of urbanization and non-family service organizations, the neighborhood land area used for agriculture still has a powerful influence on young women in this setting. Rarely have studies in the past had an opportunity to examine the effects of agricultural land use net of the influence of community characteristics. Although we cannot directly evaluate it with these data, it seems quite plausible that the returns to child labor are driving the relationship.

In contrast to the effects of agricultural land, the proportion of land area devoted to public infrastructure (schools, roads, canals, mills, other buildings, and temples) encourages women to delay childbearing, as we expected. Again this effect is net of the community characteristics mentioned above. One interesting point is that, although we failed to find statistically significant effects of neighborhood wealth, distance to urban center, and non-family service organizations within a 15-min walk, we did find a statistically significant effect of the land area devoted to public infrastructure. This suggests that for young women in Chitwan, changes within their own neighborhood are more important than the changes around their neighborhood. This finding is consistent with the argument that the more proximate the changes are, the stronger their effects on individuals. It might be noted, as well, that the results for the effects of land used for public infrastructure were not as strong as those for agricultural land. A probable explanation for this is that the concept of land under public infrastructure is less straightforward - that is, there are many other uses to which the land could be put and it is possible that the effect of a canal, for example, would be different than the effect of a school or even a road.

To conclude, this study represents settings that are rapidly changing from rural agricultural communities toward more urbanized non-agricultural communities and provides important insights about the human-land relationship at the level of the 
local community. The findings of this study provide empirical evidence for the theoretical argument that variation in land use at a local level has important influences on individuals' daily social lives, including their fertility behaviors. Findings also suggest that while land area devoted to agricultural use encourages the historical fertility behavior higher rates of first birth), land area devoted to other uses discourages such behavior and encourages new fertility behavior (lower rates of first birth).

Furthermore, consistent with the mode of social organization framework and modernization theories, the findings of this study suggest that, as rural communities start building more public infrastructure, they are likely to adopt new family formation behaviors, including the postponement of first birth.

In light of the very young age at childbearing in most of the agricultural communities of the world that is associated with a higher total number of children per mother, poorer mother-child health, higher child mortality, more frequent marital disruption, lower educational achievement, and poorer economic performance, findings of this study should provide important insights to the public policymakers of regions of the world that do not appear to be responding to family planning programs and efforts.

Acknowledgements This research was supported by a grant from the National Institute of Child Health and Human Development (grant \#R01-HD33551) and a center grant from the Fogarty International Center to Population Studies Center at the University of Michigan. We thank William G. Axinn (PI) for his guidance and providing access to the data. We also would like to thank staff of Population and Ecology Research Laboratory, the Institute for Social and Environmental Research in Nepal for their contributions to the research reported here.

\section{References}

Acharya, L. B. (1998). Determinants of fertility in the 1970s and 1990s in Nepal. Contribution to Nepalese Studies, 25(special issues), 95-108.

Acharya, M., \& Bennett, L. (1981). The status of women in Nepal (Vol. II). Centre for Economic Development and Administration Tribhuvan University Kathmandu.

Alexander, J. C. (1988). Action and its environments: Toward a new synthesis. New York: Columbia University Press.

Allison, P. D. (1982). Discrete-time methods for the analysis of event histories. Sociological Methodology, 13, 61-98.

Allison, P. D. (1995). Survival analysis using the SAS system: A practical guide. SAS Institute Inc.

Axinn, W. G., \& Barber, J. S. (2001). Mass education and fertility transition. American Sociological Review, 66(4), 481-505.

Axinn, W. G., \& Ghimire, D. J. (2002). Population and environment: the impact of fertility on land use in an agricultural society. Paper presented at the 2002 Annual Meeting of the Population Association of America, Atlanta, GA.

Axinn, W. G., \& Yabiku, S. T. (2001). Social change, the social organization of families, and fertility limitation. American Journal of Sociology, 106(5), 1219-1261.

Axinn, W. G., Barber, J. S., \& Ghimire D. J. (1997). The neighborhood history calendar: A data collection method designed for dynamic multilevel modeling. Sociological Methodology, 27, 355-392.

Axinn, W. G., Pearce, L. D. \& Ghimire, D. (1999). Innovations in life history calendar applications. Social Science Research, 28, 243-264.

Awasthi, K. D., Singh, B. R., Sitaula, B. K., \& Bajacharya, R. M. (2002). Land use change in two Nepalese watersheds: GIS and Geomorphometric analysis. Land Degradation and Development, 13, 495-523. 
Barber, J. S. (2001). Ideational influence on the transition to parenthood: attitudes toward childbearing and competing alternatives. Social Psychological Quarterly, 64(2), 101-127.

Barber, J. S. (2004). Community social context and individualistic attitudes toward marriage. Social Psychology Quarterly, 67(3), 236-256.

Barber, J. S., Biddlecom, A. E., \& Axinn, W. G. (2003). Neighborhood social change and perception of environmental degradation. Population and Environment, 25(2), 77-108.

Barber, J., Shivakoti, G., Axinn, W. G., \& Gajurel, K. (1997). Sampling strategies for rural settings: A detailed example from the Chitwan Valley Family Study Nepal. Nepal Population Journal, 6(5), 193-203.

Belli, R. F. (1998). The structure of autobiographical memory and the event history calendar: Potential improvements in the quality of retrospective reports in surveys. Memory, 6, 383-406.

Bennett, L. (1983). Dangerous wives and sacred sisters: Social and symbolic roles of high caste women in Nepal. New York: Columbia University Press.

Biddlecom, A. E., Axinn, W. G., \& Barber, J. S. (2005). Environmental effects on family size preferences and subsequent reproductive behavior in Nepal. Population and Environment, 26(3), 183-206.

Billy, J. O. G., Brewster, K. L., \& Grady, W. R. (1994). Contextual effects on the sexual behavior of adolescent women. Journal of Marriage and the Family, 56, 387-404.

Bilsborrow, R. (1992). Population growth, internal migration and environmental degradation in rural areas of developing countries. European Journal of Population (Amsterdam), 8(2), 125-148.

Bilsborrow, R. F., \& DeLargy, P. F. (1991). Land use, migration, and natural resource deterioration: The experience of Guatemala and the Sudan. In K. Davis, \& M. Bernstam (Eds.), Resources, environment, and population. Oxford: Oxford University Press.

Bista, D. B. (1972). People of Nepal. Kathmandu: Ratna Pustak Bhandar.

Blaikie, P., \& Brookfield, H. (1987). Land degradation and society. London: Methuen.

Blaikie, P., Cameron, J., \& Seddon, D. (1980). Nepal in crisis: Growth and stagnation at the periphery. Delhi: Oxford University Press.

Blau, F. D., Ferber, M. A., \& Winkler, A. E. (1998). The Economics of women, men and work (3rd ed.). Prentice Hall, Inc.

Bongaarts, J. (1978). A framework for analyzing the proximate determinants of fertility. Population and Development Review, 4(1), 105-132.

Bongaarts, J. (1992). Population growth and global warming. Population and Development Review, 18(2), 299-319.

Bongaarts, J. (1996). Population pressure and food supply system in the developing world. Population and Development Review, 22(3), 483-503.

Boserup, E. (1965). The conditions of agricultural growth: The economics of agrarian change under population pressure. Chicago: Aldine Press.

Boserup, E. (1981). Population and technological change: A study of long-term trends. Chicago: The University of Chicago Press.

Brewster, K. L. (1994). Neighborhood context and the transition to sexual activity among young black women. Demography, 31(4), 603-614.

Brewster, K. L., Billy, J. O. G., \& Grady, W. R. (1993). Social context and adolescent behavior: The impact of community on transition to sexual activity. Social Force, 71(3), 713-740.

Brooks-Gunn, J., Duncan, G. J., Klebanov, P. K., \& Sealand, N. (1993). Do Neighborhoods influence child and adolescent development? American Journal of Sociology, 99(2), 353-395.

Cain, M. (1981). Risk and insurance: Perspective on fertility and agrarian change in India and Bangladesh. Population and Development Review, 7(3), 435-474.

Cain, M. (1985). On the relationship between landholding and fertility. Population Studies, 39(-), 5-15.

Cain, M. (1986). Landholding and fertility: A rejoinder. Population Studies, 40(2), 313-317.

Carr, D. L. (2004). Proximate population factors and deforestation in tropical agricultural frontiers. Population and Environment, 25(6), 585-612.

Choe, M. K., Thapa, S., \& Achmad, S. I. (2001). Surveys show persistence of teenage marriage and childbearing in Indonesia and Nepal. In S. B. Westky (Ed.), Asia-Pacific: Population and Policy. East-West Center, 58:1-4.

Clay, D. C., \& Johnson, N. (1992). Size of farm or size of family: which comes first? Population Studies, 46, 491-505.

Cohen, J. (1995). How many people can the earth support? New York: Norton. 
Coleman, J. S. (1990). Social capital in the creation of human capital. American Journal of Sociology, 94(supplement), S95-S120.

Conway, D., \& Shrestha, N. R. (1981). Causes and consequences of rural-to-rural migration in Nepal. Bloomington: Indiana University.

Coomes, O. T., Grimard, F., \& Diaz, V. (2001). Peasant farm size and family size: a causality analysis from the Peruvian Amazon. Paper presented at NEUDC Conference, Boston MA.

Dahal, D. R. (1993). Rethinking fertility transition: some observation from Nepal. In K. C. Bal Kumar (Ed.), Population Dynamics in Nepal. Kathmandu.

Dasgupta, P. (2000). Population and resources: an exploration of reproductive and environmental externalities. Population and Development Review, 26, 643-689.

Davis, K. (1963). The theory of change and response in modern demographic history. Population Index, 29(4), 345-366.

Dignan, T. (1989). Land and landlessness among rural to rural migrants in Nepal's Terai Region. International Regional Science Review, 12(2), 189-209.

Dongol, B. D., Retherford, R. D., \& Thapa, S. (1997). Declining fertility in Nepal. Asia-Pacific Population Journal, 12, 33-54.

Durkheim, E. (1984) [1933]. The division of labor in society. New York: Free Press.

Easterlin, R. A., \& McCrimmins, E. M. (1985). The fertility revolution: a demand-supply analysis. Chicago, IL: University of Chicago Press.

Eckholm, E. P. (1976). Losing ground: environmental stress and world food prospects. New York: W. W. Norton.

Ehrlich, P. R., Ehrlich, A. H. \& Daily, G. C. (1993). Food security, population, and environment. Population and Development Review, 19(1), 1-32.

Entwisle, B., Walsh, S. J., Rindfuss, R. R., \& Chamratrithirong, A. (2003). Land-use/land-cover and population dynamics, Nang Rong, Thailand. In D. Liverman, E. F. Moran, R. R. Rindfuss, \& P. C. Stern (Ed.), People and pixels; linking remote sensing and social science (pp. 121-144). Washington, DC: National Academic Press.

Evans, T. P., \& Moran, E. F. (2002). Saptial integration of social and biophysical factors related to land cover change. Population and Development Review, 28(supplimnet), 165-186.

Fischer, C. S. (1982). To dwell among friends: Personal networks in town and city. Chicago: University of Chicago Press.

Foster A. D., \& Rosenzweig, M. R (2003). Economic growth and the rise of forest. The Quarterly Journal of Economics, 118(2), 601-637.

Foster A. D., \& Rosenzweig, M. R. (2004). Agricultural productivity growth, rural economic diversity, and economic reforms: India, 1970-2000. Economic Development and Cultural Change, 52(3), 509-542.

Fox, J. M. (1987). Livestock ownership patterns in a Nepali village. Mountain Research and Development, 7(2), 169-172.

Fox, J. (1993). Forest resources in a Nepali village in 1980 and 1990: The positive influence of population growth. Mountain Research and Development, 13, 89-98.

Freedman, D., Thornton, A., Camburn, D., Alwin, D., \& Young-DeMarco, L. (1988). The life history calendar: A technique for collecting retrospective data. Sociological Methodology, 18, 37-68.

Fricke, T. E. (1988). Himalayan households: Tamang demography and domestic processes. UMI Research Press.

FRI. (1999). Forest Resources Inventory. Ministry of Forest and Soil Conservation, His Majesty's Government of Nepal Kathmandu.

Ghimire, D. J. (2003). The social context of first birth timing in Nepal. Unpublished Ph.D.dissertation, (Ann Arbor, MI: The University of Michigan).

Ghimire, D. J. (2004). The social context of first birth timing in Nepal. Paper presented at the Annual Meeting of the Population Association of America, April 1-3, Boston, MA.

Ghimire, D. J., \& Mohai, P. (2005). Environmentalism and contraceptive use: How people in less developed settings approach environmental issues. Population and Environment, 27(1), $29-61$.

Ghimire, D. J., Axinn, W. G., Yabiku, S. T., \& Thornton, A. (2006). Social change, premarital non-family experiences and spouse choice in an arranged marriage society. American Journal of Sociology, 111(4), 1181-1218.

Goldewijk, K. K. (2001). Estimating global land use change over the past 300 years-The HYDE database. Global Biogeochemical Cycles, 15(2), 417-433. 
Good, M. D., Farr, G. M., \& Good, B. J. (1980). Social status and fertility: A study of a town and three villages in Northwestern Iran. Population Studies, 34(2), 311-319.

Gurung, H. B. (1980). Vignettes of Nepal. Kathmandu: Sajha Prakashan.

Gurung, H. B. (1998). Nepal social demography and expressions. New Era: Kathmandu.

Guthman, J. (1997). Representing crisis: the theory of Himalayan environmental degradation and the project of development in Post-Rana Nepal. Development and Change, 28(-), 45-69.

Hiday, V. A. (1978). Agricultural organization and fertility. Social Biology, 25, 69-79.

His Majesty's Government. (2001). National population census summary sheet. Statistical pocket book of Nepal 2001. Ramasha Path, Kathmandu: National Planning Commission, Central Bureau of Statistics.

Hogan, D., \& Astone, N. M. (1986). The transition to adulthood. Annual Review of Sociology, 12, $109-130$.

Hogan, D., \& Kitagawa, E. M. (1985). The impact of social status, family structure, and neighborhood on fertility of black adolescents. American Journal of Sociology, 90(4), 825-855.

Ives, J., \& Messerli, B. (1989). The Himalayan dilemma: Reconciling development and conservation. New York: Routledge.

Jencks, C., \& Mayer, S. (1990). The social consequences of growing up in a poor neighborhood: A review. In M. McGreay, \& L. Lynn. (Eds.), Concentrated urban poverty in America. Washington, DC: National Academy.

Jensen, E. R. (1990). An economic analysis of the old-age security motive for childbearing. International Economic Review, 31(4), 953-968.

Jolly, C. L., \& Torrey, B. B. (1993). Population and land use in developing countries. Washington, DC: National Academy Press.

Karan, P. P., \& Iijima, S. (1985). Environmental stress in the Himalaya. Geographical Review, 75(1), 71-92.

Kmenta, J. (1986). Elements of econometrics (2nd ed.). New York: Macmillan Publishing Company.

Lobao, L. M., \& Brown, L. A. (1998). Development context, regional differences among young women and fertility: The Ecuadorean Amazon. Social Forces, 76, 819-849.

Lambin, E. F. (1997). Modeling and monitoring land cover change processes in tropical regions. Progress in Physical Geography, 21, 375-393.

Lambin, E. F., Rounsevell, M. D. A., \& Geist, H. J. (2000). Are current agriculture land use model able to predict changes in land-use intensity? Agriculture, Ecosystem and Environment, 82, 321-331.

Liu, J., An, L., Batie, S. S., Liang, Z., Linderman, M. A., Mertig, A. G., Ouyang, Z., \& Qi, J. (2003). Human impact on land cover and panda habitat in Wolong Nature Reserve. In J. Fox, R. R. Rindfuss, S. Walsh, \& V. Mishra (Eds.), People and the environment: Approaches for linking household and community survey to remote sensing and GIS (pp. 241-263). Boston: Kluwer Academic Publishers.

Liu, J., An, L., Batie, S. S., Bearer, S. L., Chen, X., Groop, R. E., He, G., Liang , Z., Linderman, M. A., Mertig, A. G., Ouyang, Z., Qi, J., Zang, H., \& Zhou, S. (2005). Beyond population size: Examining intricate interactions among population structure, land use and environment in Wolong Nature Reserve, China. In National Research Council's Population, Land use and Environment. Washington, D.C.: National Academies Press.

Lloyd, K. M., \& South, S. J. (1996). Contextual influence on young men's transition to first marriage. Social Force, 74(3), 1097-1119.

Lutz, W., Schrebov, S., Prskawetz, A., \& Feichtinger, G. (2002). Population, natural resources, and food security: Lesson from comparing full and reduced form models. Population and Development Review, 28(supplement), 199-224.

Malthus, T. R. (1798). An essay on the principle of population. reprinted, In P. Appleman (Ed.), An essay on the principle of population (pp. 15-139). New Work: W. W. Norton.

McNicoll, G. (1980). Institutional determinants of fertility. Population and Development Review, 6(3), 441-462.

McNicoll, G. (2002). Managing population and environment systems: Problem of institutional design. Population and Development Review, 28(supplement), 144-164.

Mead, G. H. (1967). Mind, self, and society: From the standpoint of a social behaviorist. Chicago: University of Chicago Press.

Meyer W. B., \& Turner, B. L. (1992). Human population growth and global land use/cover change. Annual Review of Ecological and Systematics, 23, 34-61. 
Metz, J. J. (1991). A reassessment of the causes and severity of Nepal's environmental crisis. World Development, 19(7), 805-820.

Mills, C. W. (1959). The sociological imagination. Oxford University Press, Inc.

Ministry of Health, Population (MOHP) [Nepal], New Era, and Macro International. (2007). Nepal demographic and health survey (2006). Kathmandu Nepal: Ministry of Health and Population, New ERA and Macro International Inc.

Ministry of Health [Nepal], New Era, ORC Macro. (2002). Nepal demographic and health survey (2001). Calverton, MD, USA: Family Health Division, Ministry of Health; New EERA; and ORC Macro.

Mortimore, M. (1993). Land transformation under agricultural intensification. In C. L. Jolly, \& Torry, B. B. (Eds.) Population and land use in developing countries. Washington, DC: National Academy Press.

Mosher W. D., \& McNally, J. W. (1991). Contraceptive use at first intercourse: United States, 1965-1988. Family Planning Perspectives, 23(3), 108-116.

Pearce, L. D. (2000). The multidimensional impact of religion on childbearing preference and behavior in Nepal. Unpublished Ph. D. dissertation. University Park, PA: The Pennsylvania State University.

Petersen, T. (1991). The statistical analysis of event histories. Sociological Methods and Research, 19, 270-323.

Pichon, F. J. (1997). Settler household and land-use patterns in amazon frontier: Farm-level evidence from Ecuador. World Development, 25(1).

Retherford, R. D., \& Thapa, S. (1998). Fertility trends in Nepal 1977-1995. In S. Thapa, S. G. Neidell, \& D. R. Dahal (Eds.), Contributions to Nepalese studies: Fertility transition in Nepal. Journal of Center for Nepal and Asian Studies, Tribhuvan University, Kirtipur, Nepal, Vol. 25(special issue), 9-58.

Satayavada, A., \& Adamchak, D. J. (2000). Determinants of current use of contraception and children ever born in Nepal. Social Biology 47(1-2), 51-61.

Schmidt-Vogt, D. (1994). Deforestation in the Nepal Himalaya: Causes, scope, consequences. European Bulletin of Himalayan Research, 7, 18-24.

Schutjer, W. A., Stoke, C. S., \& Poindexter, J. R. (1983). Farm size, land ownership, and fertility in rural Egypt. Land Economics, 59, 393-403.

Shivakoti, G., Axinn, W. G., Bhandari, P., \& Chhetri, N. (1999). The impact of community context on land use in an agriculture society Population and Environment; A Journal of Interdisciplinary Studies, 20(3), 191-213.

Shrestha, N. R. (1993). Nepal: "the society and its environment". In A. M. Savada (Ed.), Nepal and Bhutan: Country studies (pp. 53-103), Washington, DC: Federal Research Division, Library of Congress.

Shrestha, V. P. (1994). Environmental problems in the Nepal Himalaya. Contributions to Nepalese Studies, 21(2), 137-151.

Shreatha, V. P. (1999). Forest resources of Nepal: destruction and environmental implications. Contributions to Nepalese Studies, 26(2), 295-307.

Shrestha, N. R., Velu, R. P., \& Conway, D. (1993). Frontier migration and upward mobility; the case of Nepal. Economic Development and Cultural Change, 41(4), 787-816.

Simmons, I. G. (1987). Transformation of the land in pre-industrial time. In M. G. Wolman, \& F. G. A. Fournier (Eds.) Land Transform in Agriculture. New York: Wiley (SCOPE).

Smith, H. L. (1989). Integrating theory and research on the institutional determinants of fertility. Demography, 26(2), 171-184.

South, S. J., \& Baumer, E. P. (2000). Deciphering community and race effects on adolescent premarital childbearing. Social Force, 78(4), 1379-1407.

South, S. J., \& Crowder, K. D. (2000). The declining significance of neighborhoods? marital transition in community context. Social Force, 78(3), 1067-1099.

Stokes, C. S. (1995). Explaining the demographic transition: Institutional factors in fertility decline. Rural Sociology, 60(1), 1-22.

Stokes, C. S., Schutjer, W. A., \& Bulatao, R. A. (1986). Is relationship between landholding and fertility spurious? a response to Cain. Population Studies, 40(2), 305-311.

Stone, L. (1978). Cultural repercussion of childlessness and low fertility in Nepal. Contribution to Nepalese Study. Journal of the Research Center for Nepal and Asian Studies Tribhuvan University Nepal, 5(2), 7-36. 
Suwal, J. V. (2001). Socio-cultural dynamics of first birth intervals in Nepal. Contribution to Nepalese Studies, 28(1), 11-33.

Thapa, S. (1989). The ethnic factor in the timing of family formation in Nepal. Asia-Pacific Population Journal, 4(1), 3-34.

Thapa, G. B. (1996). Land use, land management and environment in a subsistence mountain economy in Nepal. Agriculture, Ecosystem and Environment, 57, 57-71.

Thapa, S. (1997). Timing of family formation in the ethnic mosaic Nepal: A district_level analyses. In R. Ratnayake \& S. N. Sirimanne (Eds.), Asia-Pacific Population Journal, 12(2), 75-87.

Thapa, G. B., \& Paudel, G. S (2002). Farmland degradation in the mountains of Nepal: A study of watersheds with and without external intervention. Land Degradation and Development, 13, 479-493.

Thomas, N. (1991). Land, fertility and the population establishment. Population Studies, 40(3), 379-397.

Thornton, A., \& Fricke, T. E. (1987). Social change and the family: Comparative perspective from the West, China and South Asia. Sociological Forum, 2(4), 746-772.

Thornton, A., \& Lin, H.-S. (Eds.), (1994). Social change and the family in Taiwan. Chicago: The University of Chicago Press.

Thornton, A., Axinn, W. G., \& Teachman, J. D. (1995). The influence of school enrollment and accumulation on cohabitation and marriage in early adulthood. American Sociological Review, 60(5), 762-774.

Tiwari, P. C. (2000). Land use changes in the Himalaya and their impact on the plains ecosystem: need for sustainable land use. Land Use Policy, 17, 101-111.

Tuladhar, J. M. (1989). The onset of a fertility decline in Nepal. Asia-Pacific Population Journal, 4(3), $15-30$.

Vanlandingham, M., \& Hirschman, C. (2001). Population pressure and fertility in pre-transition Thailand. Population Studies, 55(3), 233-248.

Wolman, M. G. (1993). Population, land use, and environment: A long history. In C. L. Jolly, \& B. B. Torry (Eds.), Population and land use in developing countries. Washington, DC: National Academy Press.

Yabiku, S. T. (2004). Marriage timing in Nepal: Organizational effects and individual mechanisms. Social Forces, 83(2), 559-586.

Zajonc, R. B. (1968). The attitudinal effects of mere exposure. Journal of Personality and Social Psychology, 9(monograph supplement no. 2), 1-27. 